\title{
EVOLUCCÃO MINERALÓGICA DOS JACUPIRANGUITOS DE JACUPIRANGA (SP) DURANTE A ALTERAÇÃO INTEMPÉRICA
}

\author{
SONIA MARIA BARROS DE OLIVEIRA \& JEAN DELVIGNE
}

\begin{abstract}
MINERALOGICAL EVOLUTION OF JACUPIRANGUITES FROM JACUPIRANGA (SP) DURING WEATHERING ALTERATION. Samples were collected from a weathering profile developed above pyroxenites belonging to the alkaline massif of Jacupiranga. The primary minerals titanoaugite, magnetite, perovskite, phlogopite, and olivine - were first partially transformed by a hydrothermal alteration process and the completely altered by weathering. The earlier products of the supergene alteration of the pyroxenites are smectites; these minerals change into kaolinite and goethite which are the principal components of the lateritic cover. This paper deals with micromorphological aspects of these transformations.
\end{abstract}

INTRODUÇÃo O complexo alcalino de Jacupiranga situa-se a cerca de $200 \mathrm{~km}$ a sudoeste da cidade de São Paulo e cobre um área de aproximadamente $65 \mathrm{~km}^{2}$. Apresenta forma ovalada, com eixo maior de direção NNW. Suas rochas dominantes são ultramáficas: dunitos na porção norte e jacupiranguitos na porção sul (Melcher 1954). O clima da região é tropical úmido, com verões quentes, invernos temperados e precipitação sempre abundante.

A alteração intempérica que atuou sobre as variedades ultramáficas do complexo gerou um espesso manto laterítico que ultrapassa $40 \mathrm{~m}$. O perfil de alteração derivado dos dunitos caracteriza-se por apresentar um nível de silcrete, subjacente ao qual ocorrem concentraçōes niqueliferas (Oliveira \& Trescases 1985). A evolução dos jacupiranguitos levou à formação de um perfil enriquecido em titânio nos níveis superiores. Sobre ambas as litologias, os horizontes mais superficiais da cobertura laterítica mostram evidências de aporte coluvionar (Oliveira et al. 1987).

O objetivo deste trabalho $\varepsilon$ o de estudar as transformações mineralógicas ocorridas durante a evolução supérgena dos jacupiranguitos. Entretanto essas rochas sofreram previamente alteração hidrotermal e não é possível compreender as transformaçöes supérgenas sem estudar também os efeitos da alteração hipógena. Assim, as transformaçōes mineralogicas de origem hipógena serão tambêm descritas e analisadas.

A metodologia utilizada consistiu, em primeiro lugar, na descrição macroscópica de um perfil de alteração, com a finalidade de definir e caracterizar as diferentes fácies presentes. Seguiu-se a amostragem sistemática (amostras indeformadas) de cada horizonte e, sobre cada amostra, determinação da densidade aparente, estudos por microscopia 6́ptica de transmissão e por.difração de raios-X. Em algumas poucas amostras, foram realizadas análises químicas pontuais por microssonda eletrônica.

O PERFIL DE ALTERAÇÃO O perfil amostrado aflora nos taludes da escavação de um canal com cerca de $30 \mathrm{~m}$ de profundidade. É possivel distinguir, da base para o topo, cinco diferentes horizontes em transiçöes gradacionais:

Rocha alterada (de 24 a 30 m) - Rocha de cor verde-escura a preta e densidade aparente em torno de 2,4. É um material friável devido aos veios argilosos verde-claros que entrecortam fragmentos escuros e mais consistentes. Os principais minerais presentes são a titanoaugita parcialmente alterada em esmectita, magnetita discretamente oxidada nas bordas, perovskita parcialmente transformada em anatásio e vermiculita ligeiramente ferruginizada ao longo dos planos de clivagem.

Saprólito verde (de 19 a 24 m) - Material verde, textura areno-argilosa, friável, com densidade aparente ao redor de 1,7. A cor verde gradua de tons mais escuros para tons mais claros em direção ao topo do perfil. Constitui-se essencialmente de esmectita e de restos de piroxênio e vermiculita. A magnetita permanece discretamente ferruginizada e a perovskita encontra-se totalmente transformada em anatásio.

Saprólito amarelo (de 16 a 19 m) - Este horizonte com densidade bem baixa (1,1 em média) é mais argiloso que o horizonte subjacente e mais heterogêneo, com manchas amarelas e avermelhadas, e, localizadamente, concreçőes pretas de manganês. Os minerais essenciais presentes são a esmectita, a caulinita e a goethita. Embora a porosidade deste nível seja bastante elevada, a estrutura original da rocha permanece grosseiramente conservada, podendo, localmente, encontrar-se obliterada. No saprólito amarelo são freqüentes fissuras preenchidas por material argiloso desorganizado, iluviado dos níveis superiores do perfil.

Laterita vermelho-amarelada (de 0,15 a 16 m) - É um material argiloso, vermelho mosqueado de amarelo na base do horizonte e mais violáceo em direção ao topo. Pode apresentar concreçőes ferruginosas e nele são freqüentes as acumulaçöes de manganês. Macroscopicamente, não apresenta mais vestrgios de estrutura da rocha; ao contrário, mostra-se compactado, com densidade média de 1,4. Constitui-se essencialmente por um plasma de goethita e caulinita, no qual se encontram grãos de magnetita parcialmente oxidada e fantasmas de perovskita compostos por anatásio. São abundantes traços de atividade biologica como canais deixados por vermes ou por rafzes, sobretudo na parte superior do horizonte. Grãos de quartzo detrítico estão presentes em pequena quantidade na laterita.

\footnotetext{
* Departamento de Geologia Geral, Instituto de Geociências, USP. Caixa Postal 20899, CEP 01498, São Paulo, SP, Brasil

** OSTROM, Laboratoire de Géologie Dynamique et de Pétrologie de la Surface, Facultés des Sciences et Techniques de Saint-Jerôme. 13397 Marseille Cedex 13, France
} 
Solo (de 0 a $0,15 \mathrm{~m}$ ) - Capeando o perfil, ocorre um nível escuro, rico em matéria orgânica, que não foi objeto de investigação deste trabalho.

Apesar da grande espessura deste perfil, em sua base não atlora a rocha fresca. Para se ter uma idéia do material de partida para a formação do perfil de alteração, o piroxenito fresco foi amostrado em outros afloramentos. É uma rocha de cor preta, granulação grossa e densidade elevada $(3,0)$. Compõe-se principalmente por grãos de titanoaugita em textura granoblástica. O segundo mineral mais abundante é a magnetita, ameboidal, que preenche os espaços entre os cristais de piroxênio, evidenciando cristalização tardia. Sempre associada a ela, aparece a perovskita. Distribuído heterogeneamente pela rocha, ocorre um mineral micáceo que, embora guarde as características opticas da flogopita, encontra-se parcial ou totalmente transformado em vermiculita, conforme é indicado pela difração de raios-X. Como acessórios, os jacupiranguitos apresentam principalmente olivina, nefelina, apatita e calcita.

FILIAÇÃO MINERALÓGICAS Embora o perfil de alteração estudado seja ligeiramente heterogêneo no que concerne à mineralogia do material que lhe deu origem, e as amostras de rocha fresca não correspondam exatamente àquelas encontradas na base do perfil, é possível seguir, em seu conjunto, a evolução completa da maioria dos minerais constituintes do piroxenito. Apenas alguns minerais acessorios, tais como a olivina, a hornblenda, a nefelina, a calcita, a clorita e a apatita, s6 aparecem em certos níveis do perfil de alteração. Os minerais essenciais, como o piroxênio, a magnetita, a flogogita e a perovskita, podem apresentar variaçōes quantitativas relativamente importantes pela seqüência de alteração, em conseqüência de sua distribuição irregular nas rochas originais.

$\mathrm{O}$ exame micromorfologico e mineral6gico das rochas frescas e do material proveniente da base do perfil de alteração permite distinguir dois tipos de alteração diferentes que se sucedem no tempo. $\mathrm{O}$ primeiro tipo consiste numa alteração profunda, de origem hidrotermal, que transformou parcial ou totalmente certos minerais originais, mas cuja influência sobre os minerais essenciais foi discreta e irregular. Seguiu-se uma alteração superficial, de origem meteórica, que foi responsável pela degradação da maior parte dos minerais originais e dos minerais de origem hidrotermal em minerais secundários com argilas e oxi-hidr6́xidos de ferro. Este tipo de alteração se faz cada vez mais evidente da base para o topo do perfil, por modificações importantes na alterita, no que diz respeito à composição mineralogica e química, coesão, densidade aparente e coloração.

Alteração Hidrotermal A influência da alteração hidrotermal, apesar de presente na totalidade do perfil, é cada vez menos reconhecível nos materiais de seus níveis superiores, onde a alteração intempérica é dominante e mascara quase que completamente as transformaçōes mineralogicas anteriores.

No conjunto das rochas, a alteração de origem profunda e marcada principalmente: 1. por uma certa fissuração ou fragmentação dos piroxênios; 2. pelo aparecimento, nessas fraturas, de minerais secundários, como a vermiculita, de pequena dimensão; 3. pela transformação dos piroxênios em hornblenda, talco, minessotaíta e calcita; 4. pela degradaçâo de uma parte importante da flogopita original em vermiculita de grandes dimensões; 5. pela transformação total ou parcial da olivina em "iddingsita", acompanhada, em alguns locais, de serpentina e magnetita, associadas sob forma de um reticulado limitando as pseudomorfoses da olivina.
A fissuração real ou potencial dos piroxênios, preenchida ou não por minerais secundários, tem um importante papel do desenvolvimento ulterior da alteração supérgena, facilitando a circulação das águas de origem superficial e a troca de fons entre essas águas e os minerais atravessados por elas. Os pequenos filōes de microvermiculita desenvolvidos entre os cristais de piroxênio têm o mesmo papel.

A olivina, presente em quantidades relativamente importantes em certos níveis do perfil de alteração, apresenta-se sempre profundamente alterada e transformada em minerais secundários: serpentina, "iddingsita" e esmectita (Pr. 1, Foto 1). É diff́cil definir a origem desta última. Com efeito, a olivina é ao mesmo tempo muito sensível aos processos de alteração hidrotermais e supérgenos, e, assim, a presença quase constante de esmectitas poderia ser atribuída tanto aos primeiros quanto aos segundos. Pode-se admitir, entretanto, que, quando da fase de alteração hidrotermal, uma parte apenas da olivina tenha sido transformada em serpentina, e sobretudo em "iddingsita", abandonando resíduos não alterados de olivina que teriam sido em seguida alterados em esmectita super gena. Esta hipótese ê sugerida pela constante presença de hidróxidos de ferro nas pseudomorfoses esmectíticas. No processo de alteração superficial, a serpentina se degrada e apenas a "iddingsita", mais resistente, persiste intacta como única testemunha de uma fase de alteração anterior.

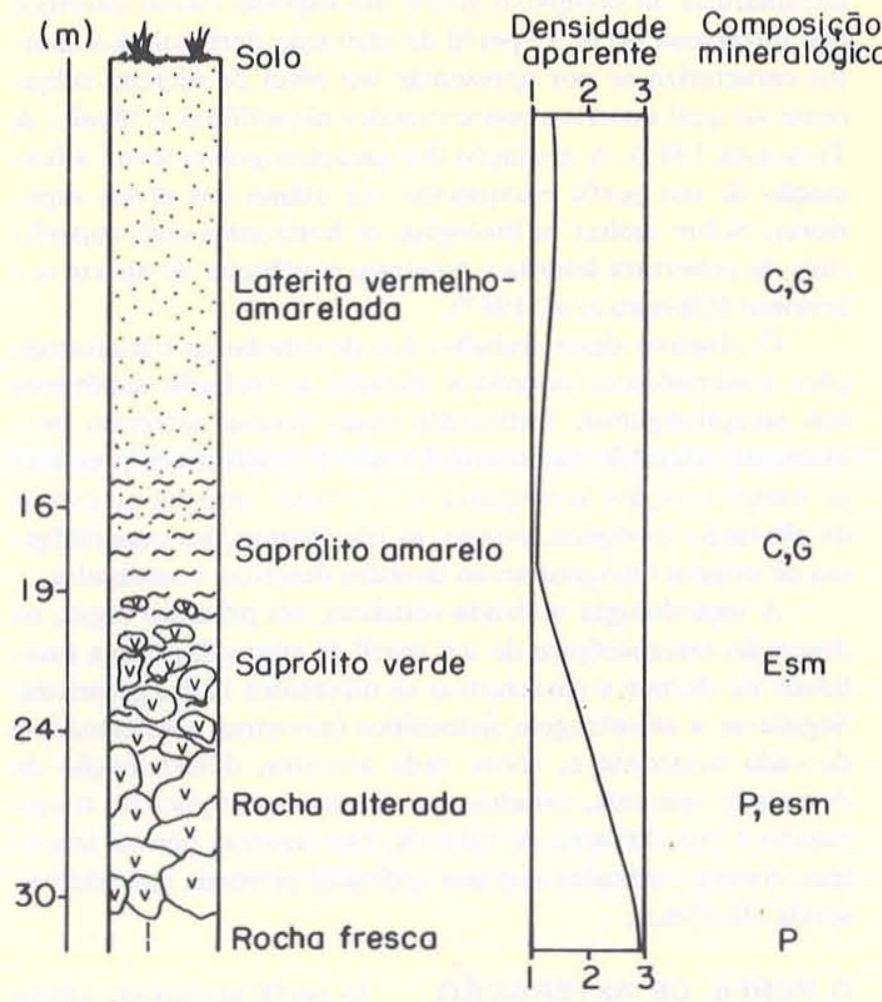

Figura 1 - $O$ perfil de alteração $(P=$ piroxênio, $E s m=e s-$ mectita, $C=$ saulinita, $G=$ geothita)

Alteração Supérgena Piroxênio - Os piroxênios representam entre $60 \%$ e $90 \%$ do volume das rochas originais e, assim sendo, sua alteração é responsável pela velocidade de 

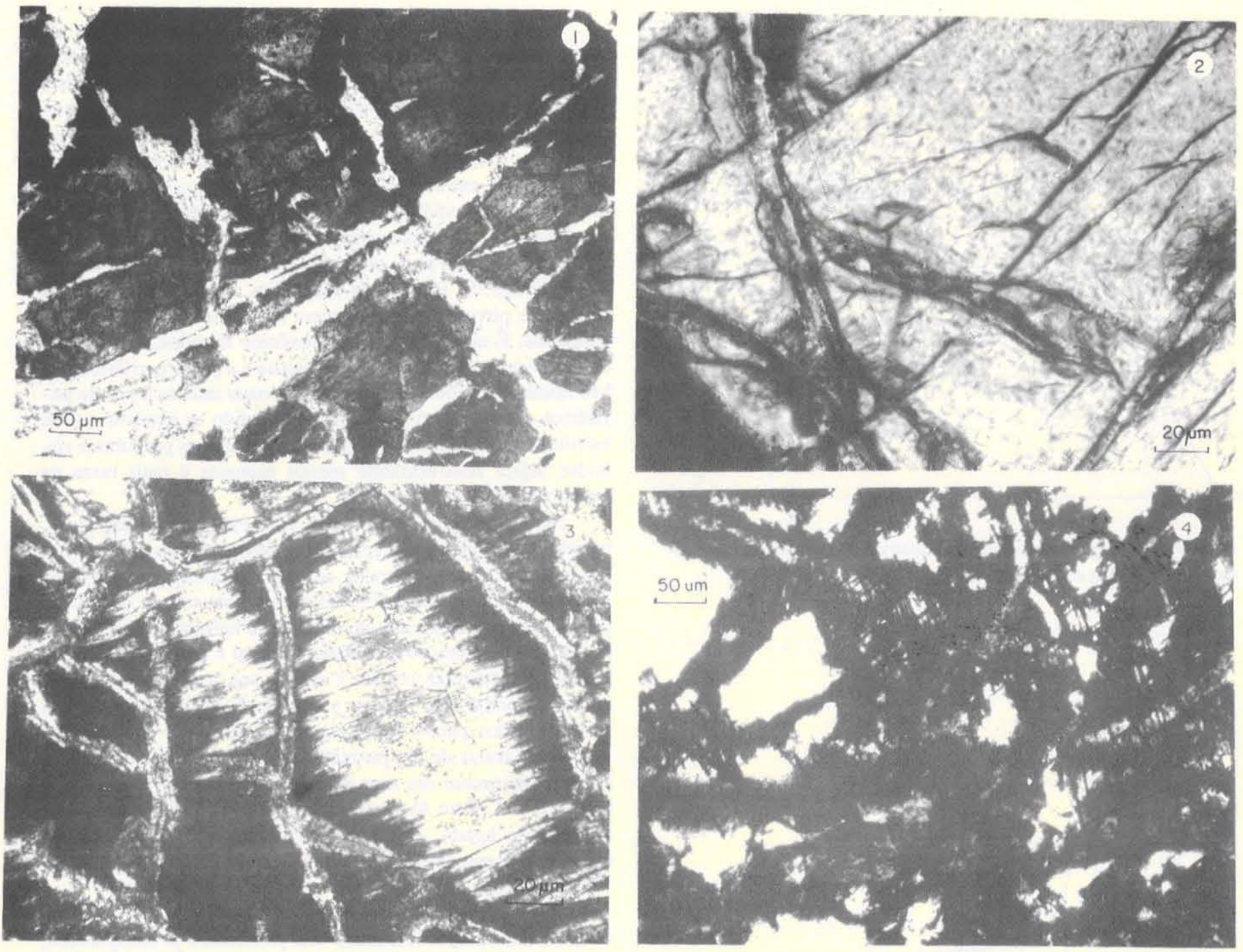

Prancha 1. Fotomicrografias. 1. Olivina alterada em esmectita. Nicóis paralelos. 2. Início da alteraçäo da titanoaugita em esmectita, ao longo das fissuras. Nicois paralelos. 3. Alteração da titanoaugita em formas denticuladas. Nicois cruzados. 4. Alteração da titanoaugita num plasma goethítico. Agulhas de magnetita permanecem no lugar original. Nicois paralelos

alteração das rochas e pela espessura das alteritas resultantes. A magnetita, pouco alterável, aparece nos níveis superficiais do perfil de alteração, sob forma de grão reliquiares. Entretanto, sua presença e sua repartição no seio das alteritas, a permanência de suas formas e suas associações com outros minerais (magnetita-perovskita, por exemplo) permitem reconhecer a natureza isovolumétrica da alteração nos níveis onde a alteração avançada dos minerais essenciais (piroxênios e flogopitas) não permitiria mais reconhecê-la.

A alteração do piroxênio progride a partir das bordas das fissuras e fraturas transversais (Pr. 1, Foto 2), com o aparecimento de manchas irregulares ou de estruturas denticuladas constituídas de esmectitas secundárias. Dados 6pticos difratométricos e de microssonda eletrônica permitiram caracterizar o piroxênio como uma titanoaugita $\left(\mathrm{TiO}_{2}\right.$ variando entre $2,5 \%$ e $3 \%$ ) e a esmectita como pertencente à família das beidellitas. A figura 2 indica, num diagrama triangular $\mathrm{Al}-\mathrm{Fe}-$ $\mathrm{Mg}$, a evolução supérgena inicial dos piroxênios.

Com o objetivo de investigar o destino do titânio, quando da transformação da titanoaugita em beidellita, foram realizadas com microssonda eletrônica análises semiquantitativas so- bre quatro pontos distintos de uma mancha opticamente homogênea de beidellita no seio de um piroxênio (Figura 3). Essas análises mostram que o conteúdo de titânio é muito variável, o que indica que provavelmente o titânio está sob forma de grâos ultramicroscópicos de anatásio heterogeneamente distribuidos na massa argilosa.

Em alguns piroxênios encontrados nas rochas de afloramentos ocorre esporadicamente um outro tipo de alteração, provavelmente de origem supérgena, restrito às amostras de rocha praticamente frescas. Trata-se de estruturas fitadas, dispostas segundo as fraturas do piroxênio e cuja composição mineralogica, simétrica em relaçẩo a um plano mediano marcado por um alinhamento de pequenos grãos castanhos (hidróxidos de ferro e de titânio), é essencialmente um material criptocristalino. Esse material é heterogêneo: próximo ao alinhamento central dos grãos, observam-se microestruturas vermiformes constituídas de um mineral finamente fibroso e de bi-refringência baixa, que parece calcedônia. No contato com as bordas denticuladas do piroxênio, inclúdo no material criptocristalino, podem-se observar cristalizações discretas de calcita. 


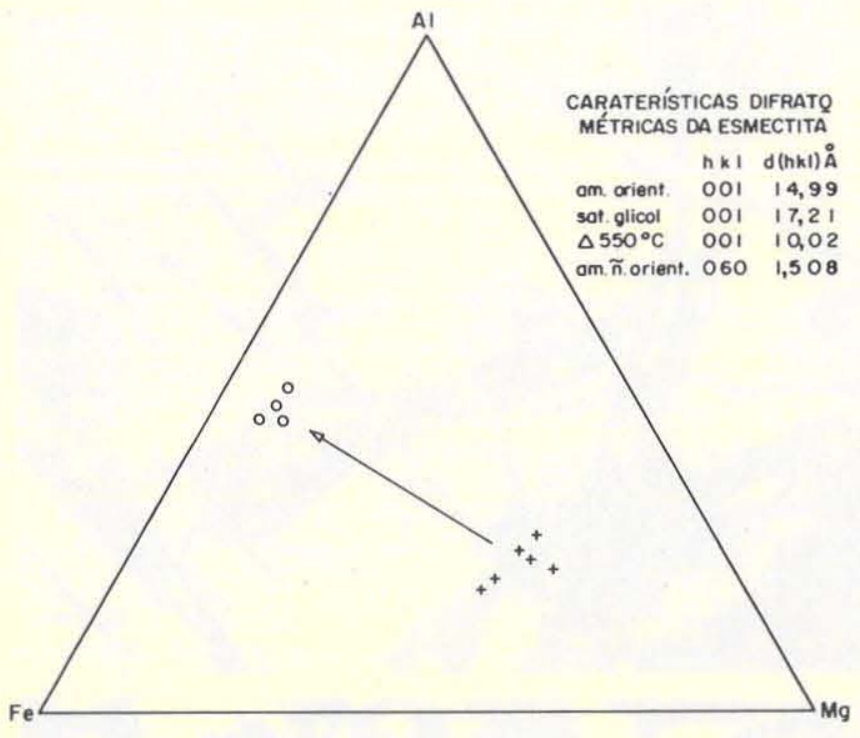

Figura 2 - Diagrama Fe-Al-Mg mostrando a evolução dos piroxênios (+) em esmectitas (o)

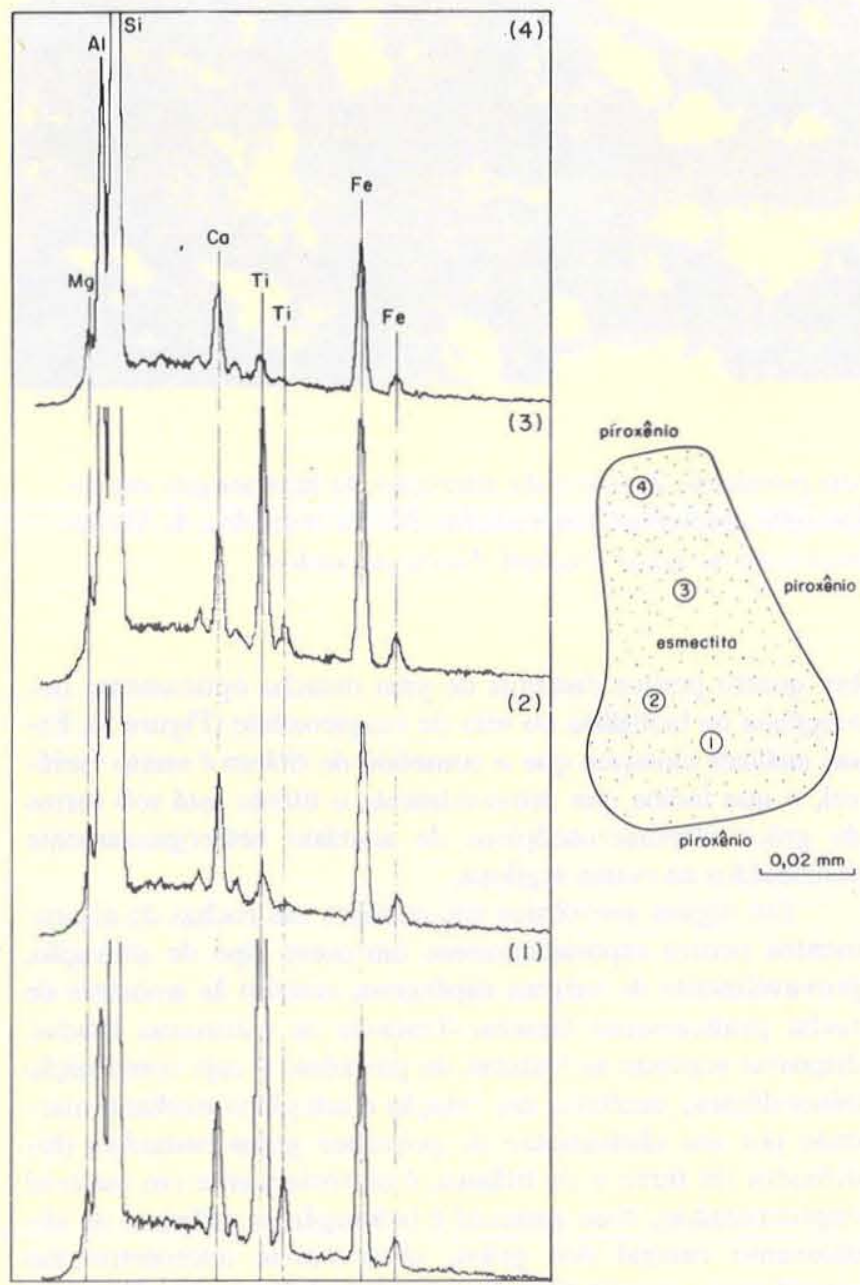

Figura 3 - Espectros obtidos por meio do Sistema Dispersivo de Energia (EDS) na microssonda eletrônica. Mancha de esmectita no seio de um piroxênio.
Seguindo a progressão da alteração do piroxênio nos niveis inferiores e médios do perfil, acima de $23 \mathrm{~m}$ de profundidade, as estruturas intraminerais vão-se espessando à custa dos núcleos residuais do piroxênio. Estes adquirem progressivamente o aspecto finamente denticulado, característico dos piroxênios em vias de alteração. As esmectitas permanecem, em geral, em estreito contato com os resíduos de piroxênios, sem fase intermediária. Localizadamente, entretanto, pode-se observar um certo deslocamento das argilas do piroxênio com a formação de um poro perinuclear entre eles (Pr. 1, Foto 3). As inclusões de agulhas de magnetita, freqüentes em certos cristais de piroxênio, desaparecem nas estruturas argilosas secundárias. É notável que nos piroxênios zonados, com a parte central rica em inclusões de magnetita e a parte periférica pobre nessas inclusões, a alteração seja mais intensa na parte periférica. Isto é posto em evidência quando se observa que as estruturas secundárias contínuas que cortam os piroxênios zonados sejam sensivelmente menos espessas e mais raras na parte central desses minerais.

No saprólito amarelo, entre 16 a $19 \mathrm{~m}$ de profundidade, os núcleos residuais dos piroxênios desaparecem rapidamente e a microestrutura da rocha se torna extremamente porosa. Enquanto as esmectitas formadas anteriormente se degradam parcialmente num plasma de caulinita e hidróxidos de ferro, a alteração completa do piroxênio residual é para goethita, que invade as estruturas prévias e se fixa sob forma de boxwork, em uma malha que lembra a orientação e a disposição das fraturas e dos planos de clivagem do piroxênio residual. No caso de se tratar de um piroxênio com inclusões de magnetita, estas permanecem em suas posições originais no plasma goethítico (Pr. 1, Foto 4). A aparição de quantidades importantes de goethita ligada, ao menos parcialmente, à degradação da esmectita, é responsável pela mudança de coloração desse nível de saprólito, que passa, assim, do verde ao amarelo.

No nível laterítico vermelho-amarelado, acima de $16 \mathrm{~m}$ de profundidade, a totalidade dos piroxênios já desapareceu, as esmectitas estão totalmente degradadas e o que se observa é uma estrutura muito porosa, constituída essencialmente por um pouco de caulinita e muito hidr6xido de ferro, mais ou menos bem cristalizado. As texturas originais se apagam progressivamente e apenas a disposição e a repartição do minerais pouco alteráveis, como a magnetita, ou dos minerais facilmente reconhecíveis, como a vermiculita, pseudomorfizada pela caulinita, permitem afirmar que a estrutura geral da rocha original é mais ou menos conservada (alteração isovolume) até em torno de $5 \mathrm{~m}$ de profundidade.

Acima disso até a superfície, apenas alguns pseudomorfos isolados, quebrados e incompletos, lembram a textura petrográfica original. É o domínio da pedoturbação e da atividade biologica. É também o domínio do remanejamento e do coluvionamento, responsáveis pela presença de numerosos grãos de quartzo observados no nível superior e cuja origem al6ctone é evidente.

Olivina - A olivina, sempre alterada, s6 aparece no perfil entre 20 e $15 \mathrm{~m}$ de profundidade em conseqüência da heterogeneidade da rocha original. Este é um nível relativamente elevado do perfil, no qual os minerais menos alteráveis que aquele mineral já estão quase totalmente alterados. Nestas condições, a olivina fresca, mesmo sob forma de núcleos residuais, não foi observada neste perfil.

Transformada anteriormente em "iddingsita", às vezes associada a um pouco de serpentina, os núcleos residuais eventuais foram, quando da alteração supérgena, totalmente alterados em esmectita verde, provavelmente nontronítica. A 
"iddingsita", relativamente estável neste nível de alteração superficial, degrada-se lentamente em hidróxidos de ferro formando manchas contínuas, não porosas, orientadas, muito diferentes das pseudomorfoses ferruginosas formadas pela alteração dos piroxênios vizinhos. Fragmentos esparsos de "iddingsita" são encontrados até no nível superior do perfil em associação com as palhetas de vermiculita degradada e com os grãos de quartzo.

As esmectitas formadas à custa da olivina têm o mesmo destino daquelas originadas dos piroxênios: degradação em caulinita com exsolução de hidróxidos de ferro.

Flogopita - Nas rochas frescas dos afloramentos, a flogopita é rara e se apresenta como conjunto de cristais ameboides entre os grãos de piroxênio, da mesma forma que a magnetita. Nas rochas do perfil alterado, a flogopita é muito mais abundante ocupando a mesma posição. No nível inferior da alterita, é relativamente freqüente e está sempre parcialmente alterada em vermiculita, sob forma de acumulações micáceas irregulares, curvadas e fraturadas. Vermiculita de menor tamanho aparece freqüentemente nas juntas abertas entre os piroxênios ou nas fraturas que os atravessam.

A transformação supérgena da vermiculita se faz segundo duas vias diferentes. Desde o saprólito verde, aparecem associadas à vermiculita, ou eventualmente à flogopita residual, pequenas manchas de esmectitas verdes, não orientadas em concordância com as folhas originais e muito semelhantes àquelas que se desenvolvem ao mesmo tempo a partir dos piroxênios. Na parte superior deste nível, e sobretudo no nível de saprólito amarelo, a esmectita neoformada começa a se degradar da mesma maneira que as esmectitas provenientes dos piroxênios. A partir da vermiculita residual, desenvolve-se caulinita entre suas lamelas formando pacotes de espessuras variáveis (Pr. 2, Foto 5). A caulinita, incolor e límpida, em contraste com a vermiculita fortemente colorida, é marcada pela presença de numerosas inclusões cinzentas, quase opacas, que lembram inclusões de minerais titaníferos.

No nível de laterita, a caulinita de degradação das micas 6 cada vez mais abundante, embora persistam relíquias de vermiculita inalterada ou colorida pelos hidróxidos de ferro. Es-
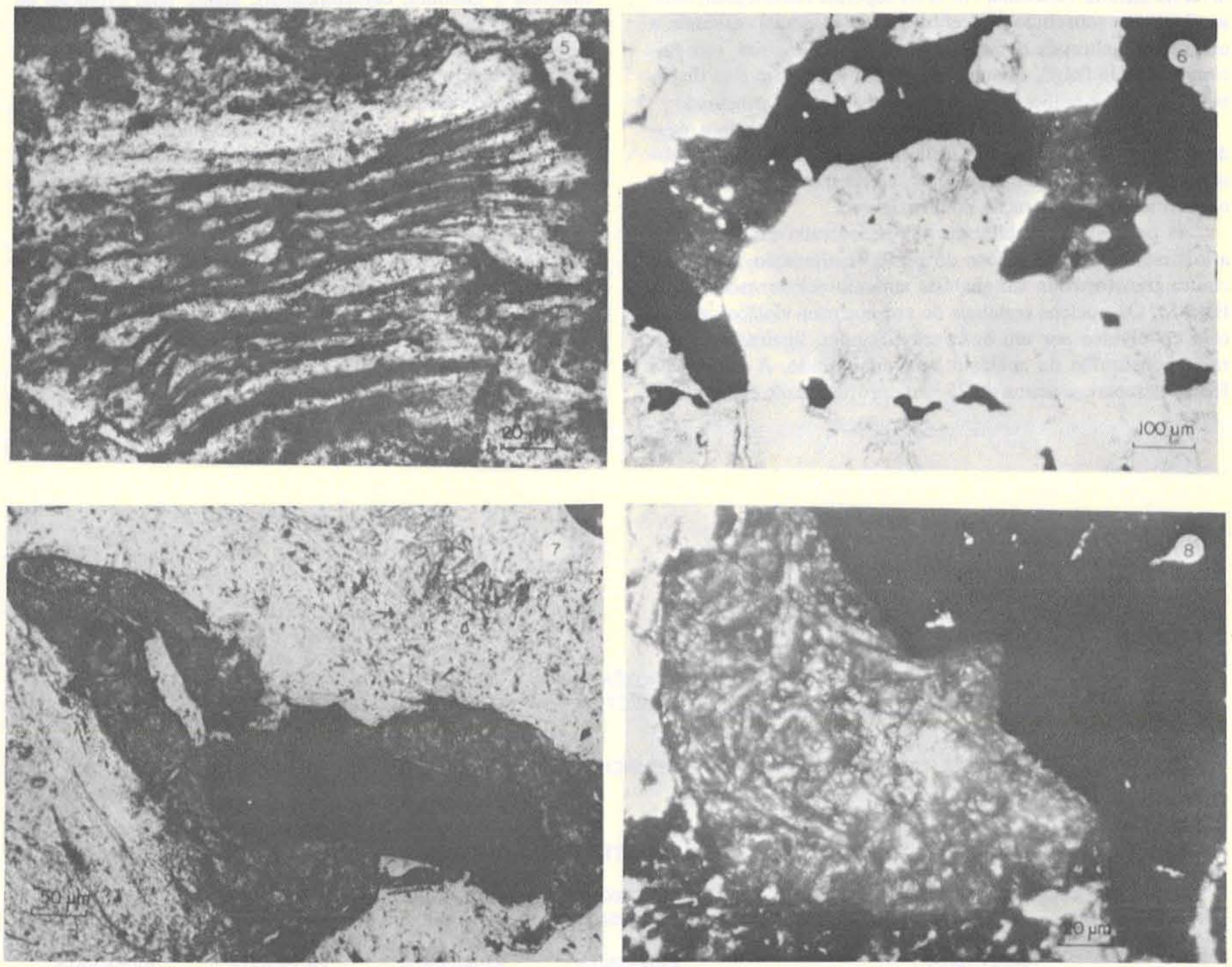

Prancha 2. Fotomicrografias. 5. Alteração da flogopita em caulinita. Nicóis paralelos. 6. Magnetita (preto) e perovskita (cinza) na rocha fresca. Nicois paralelos. 7. Perovskita alterada em leucoxênio envolvendo a magnetita. Nicóis paralelos. 8. Perovskita alterada em leucoxênio e anatásio. Nicóis paralelos. 
sas relíquias se encontram também ao nível superior atingido pelo coluvionamento, associadas à caulinita e a fragmentos de "iddingsita" e quartzo.

Associação magnetita-perovskita - A magnetita e perovskita estão quase sempre associadas nas rochas estudadas. A perovskita, entretanto, não aparece senão quando a quantidade de magnetita da rocha ultrapassa $8 \%$ do volume. Os dois minerais, totalmente xenomorfos, de formas ameboides, situamse sempre entre os cristais de piroxênio e/ou de flogopita (Pr. 2, Foto 6). $\mathrm{O}$ limite interno entre os dois minerais associados é nítido e, em casos em que a associação é mais complexa, a perovskita se concentra de preferência na parte externa da associação, mais diretamente em contato com os silicatos ( $\mathrm{Pr}$. 2, Foto 7).

A magnetita encontra-se também isolada sob forma de inclusões finamente prismáticas ou aciculares seguindo os planos de clivagem da parte central dos piroxênios zonados.

A alteração por oxidação e hidratação da magnetita é dificilmente observável ao microscópio óptico de transmissão por causa da opacidade da magnetita e dos minerais neoformados. Entretanto, com luz condensada, é possível observar a transformação parcial da magnetita em hemetita a partir do nível de laterita vermelha. No nível superior remanejado, onde se observam sobretudo concentraçōes de minerais residuais, a magnetita inalterada domina novamente; a hematita, mecanicamente mais frágil, dissocia-se de seu suporte e fica distribuída em grãos muito finos no fundo matricial avermelhado.

As inclusões de magnetita desaparecem mais cedo e, desde o início da alteração dos jacupiranguitos, elas não são observadas, senão raramente, nas estruturas das esmectitas neoformadas por alteração do piroxênio.

A perovskita não alterada sర é encontrada nas rochas dos afloramentos. Desde a base do perfil de alteração, ela se encontra transformada em anatásio amarelo-acinzentado (Pr. 2, Foto 8). Os núcleos residuais de cor marrom-violácea aparecem envolvidos por um boxwork irregular, ligeiramente poroso, constituído de anatásio bem cristalizado. A perovskita fresca desaparece acima de $25 \mathrm{~m}$ de profundidade enquanto as pseudomorfoses de anatásio se mantêm intactas até o nível superior da alterita e mesmo no nível remanejado. Neste, os minerais titaníferos de origem secundária podem concentrar-se por acumulação relativa, dada sua marcada inalterabilidade. Ainda neste nível, ao lado das pseudomorfoses em boxwork com anatásio bem cristalizado estão misturadas com manchas irregulares de anatásio criptocristalino branco-acinzentado, praticamente opaco, cuja origem deve ser aloctone ao perfil de alteração, já que elas não estão presentes nos níveis autóctones da alterita subjacente.

A figura 4 resume as relaçōes de filiação entre os minerais primários e secundários.

CONSIDERAÇÕES FINAIS O estudo micromorfologico dos diferentes estágios de alteração do jacupiranguito permitiu evidenciar a transformação de uma assembléia mineralógica primária afetada por transformações hipógenas numa assembléia essencialmente secundária, gerada pelos agentes do intemperismo, em que o único mineral primário que permanece residualmente ế a magnetita. A alteração supérgena dos silicatos hipógenos (titanoaugita, vermiculita e olivina) levou à formação de argilas 2:1, que acabaram por se degradar em caulinita e goethita, caracterizando, assim, uma evolução de tipo laterítica. Evolução semelhante de piroxênios, sob clima tropical, foi descrita em Carajás (Bernardelli et al. 1983), Costa do Marfim (Nahom et al. 1982), Barro Alto (Trescases \& Oliveira 1981) e Niquelândia (Oliveira \& Trescases 1982, Colin et al. 1985), no caso de ortopiroxênios, e em Santa Fé (Oliveira 1980), no caso de diopsídio. Kimpe et al. (1987) mostraram que a evolução de augitas sob clima temperado também se dá no sentido da formação de esmectitas, mas, ao contrário do que acontece em condiçőes climáticas mais agressivas, esses minerais não se degradam constituindo o principal componente dos solos.

A transformação da perovskita em anatásio e a neoformação de minerais de titânio a partir da titanoaugita são, neste caso, os mecanismos responsáveis pela concentração supérgena deste elemento.

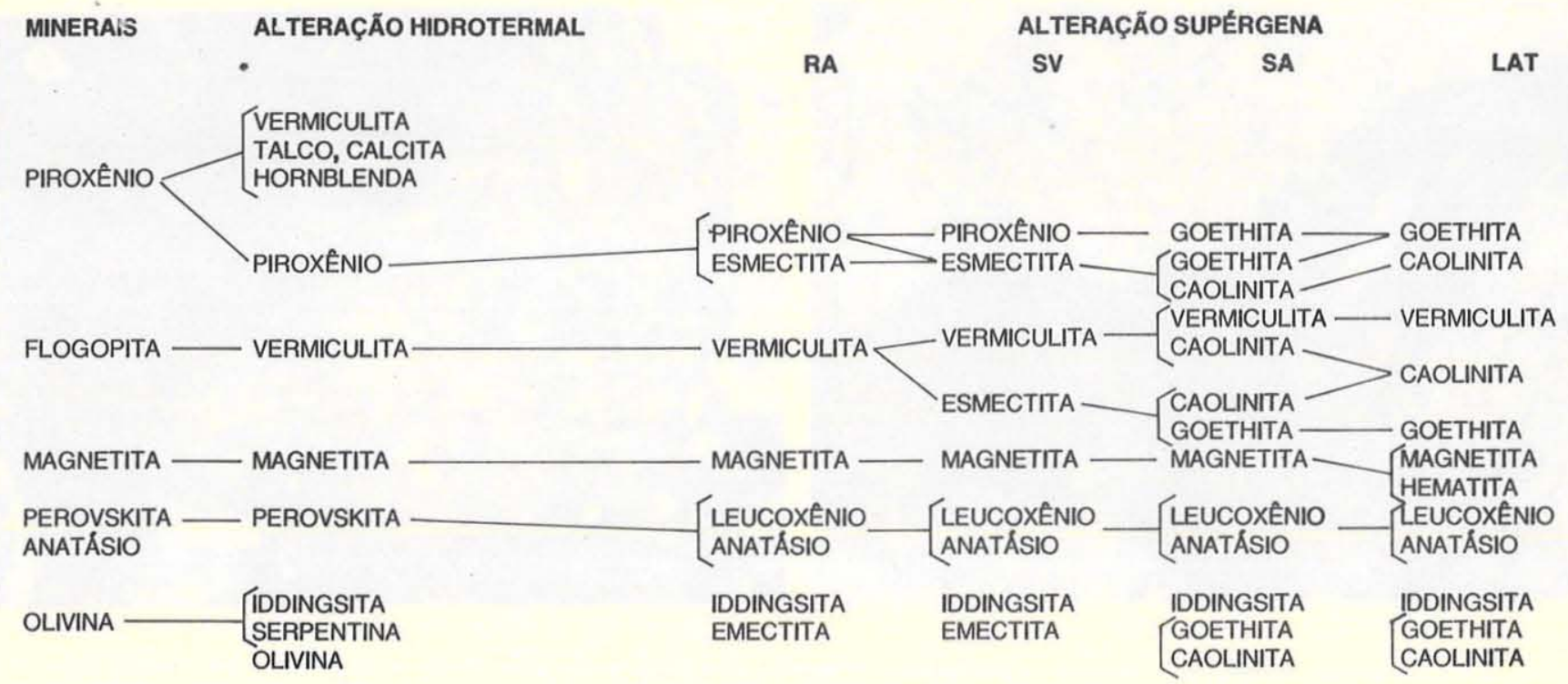

Figura 4 - Filiaçöes mineralogicas $(R A=$ rocha alterada, $S V=$ saprolito verde, $S A=$ saprolito amarelo, $L A T=$ laterita $)$ 


\section{REFERÊNCIAS BIBLIOGRÁFICAS}

BERNARDELLI, A.; MELFI, A.J.; OLIVEIRA, S.M.B. de; TRES CASES, J.J. 1983. The Carajás nickel deposits. In: INT. SEM. LAT. PROC. 2, São Paulo, 1982. Proceed... São Paulo, IGCP. 129 and IAGC. p. 107-118.

COLIN, F.; NOACK, Y.; TRESCASES, J.J.; NAHON, D. 1985. L'altération latéritique débutante des pyroxénites de Jacuba, $\mathrm{Ni}$ quelândia, Brésil. Clay Min., 20:93-113.

KIMPE, C. de; DEJOU, J.; CHEVALIER, Y. 1987. Évolution géochimique superficielle des pyroxénites ignées du Mont Saint-Bruno, Québec. Can. J. Earth Sc., 24:760-770.

MELCHER, G.C. 1954. Nota sobre o distrito alcalino de Jacupiranga, Estado de São Paulo. DNPM/DGM. 20 p. (Notas Preliminares, 84):

NAHON, D.; PAQUET, H.; DELVIGNE, J. 1982. Lateritic weathering of ultramafic rocks and concentration of nickel in Western Ivory Coast. Econ. Geol., 77:1159-1175.

OLIVEIRA, S.M.B. de. 1980. Alteração intempérica das rochas ultra básicas de Santa Fé (GO) e gênese do depósito niquelifero. São Paulo, 216 p. (Tese de Doutoramento, Instituto de Geociências da USP).
OLIVEIRA, S.M.B. de \& TRESCASES, J.J. 1982. Estudo mineralógico e geoquímico da laterita niquelífera de Niquelândia, GO. In CONGR. BRAS. GEOL., 32, Salvador, 1982. Anais... Salvador, SBG. v. 3, p. 1183-1190.

OLIVEIRA, S.M.B. de \& TRESCASES, J.J. 1985. O depósito de ní quel de Jacupiranga (SP): evolução mineralógica e geoquímica. Rev. Bras. Geoc. 15(3):249-254.

OLIVEIRA, S.M.B. de; MELFI, A.J.; CARVALHO, A.; FRIEDRICH, G.; MARKER, A.; KANIG, M. 1987. Evolução geoquímica supergênica do maciço alcalino de Jacupiranga (SP). In: CONGR. BRAS. GEOQ., 1, Porto Alegre, 1987. Breves Comunicações, Porto Alegre, SBGq.

TRESCASES, J.J.; OLIVEIRA, S.M.B. de. 1981. A jazida de níquel de Barro Alto. In: SIMP. GEOL. CENTRO-OESTE, 1, Goiânia 1981. Atas... Goiânia, SBG, p. 519-538.

MANUSCRITO 493

Recebido em 11 de setembro de 1987 Revisão aceita em 18 de dezembro de 1987

Creio que uma educação de verdade, e fiel à verdade, não pode deixar de promover e liderar, a curto ou longo prazo, uma mudança da sociedade, tendo em vista $o$ atendimento das suas reais necessidades. 